\title{
The Presence of Musculus Psoas Minor in Weightlifting Athletes of the Olympic Preparation Center ${ }^{i}$
}

\author{
Kenan Erdağı 1,"*, Necdet Poyraz ${ }^{2}$, Hüseyin Aslan³, Bülent Işık ${ }^{4}$, Sadullah Bahar ${ }^{5}$ \\ ${ }^{1}$ Department of Physical Education and Sports, Faculty of Education, Necmettin Erbakan University, Konya, Turkey \\ ${ }^{2}$ Department of Radiology, Meram Faculty of Medicine, Necmettin Erbakan University, Konya, Turkey \\ ${ }^{3}$ Faculty of Sport Sciences, Selcuk University, Konya, Turkey \\ ${ }^{4}$ Provincial Health Directorate, Konya, Turkey \\ ${ }^{5}$ Department of Anatomy, Faculty of Veterinary, Selcuk University, Konya, Turkey
}

Copyright $\bigcirc 2018$ by authors, all rights reserved. Authors agree that this article remains permanently open access under the terms of the Creative Commons Attribution License 4.0 International License

\begin{abstract}
The study aims to analyze the presence of musculus psoas minor through axial magnetic resonance imaging obtained from national weightlifting athletes. The study included 12 men and 12 women national weightlifting athletes having trained regularly and participated in national and international tournaments. Axial imaging from the $12^{\text {th }}$ thoracic vertebrae to the trochanter minor of femur was taken by using 1.5 Tesla magnetic imaging device. In our study including 24 athlete participants in total, we found out that the muscle is generally present on double sides of $29.16 \%$, on the right side only of $8.33 \%$ and on the left side only of $8.33 \%$ of the participants. The muscle was not present on $54.16 \%$ of the participants. As a result, we conclude that the absence of musculus psoas minor in weightlifting athletes may be considered as a disadvantage factor for athletic skills.
\end{abstract}

Keywords Musculus Psoas Minor, Magnetic Resonance Imaging, Olympic Weightlifting

\section{Introduction}

Olympic-style weightlifting is a type of weightlifting sports in which athletes perform snatch and clean-and-jerk techniques $[1,2]$. The passive elements of the mostly activated lumbar region during weightlifting and body movements include lumbar vertebras, facet joints and areal ligaments, whereas the active elements include abdominal muscles, paravertebral and posterior abdominal wall muscles [3,4]. In Olympic-style weightlifting, lumbar injuries are quite widespread [5], thus, the balance, trunk and lumbar stabilization plays a critical role [6]. During dynamic and static workloads, the health of lumbar region is directly related to the strength of areal muscles [7]. One of the muscles in the lumbar region, musculus psoas minor (PSMI), originating from the sides of the bodies of the $12^{\text {th }}$ thoracic and first lumbar vertebrae and intervening intervertebral disk between them is a long and cylindrical muscle, whose muscular part lies anterior to and whose tendinous part stretches along the medial side of musculus psoas major, inserted on the eminentiailiopubica [8,9]. Musculus psoas minor is a weak muscle and approximately $40 \%$ of individuals do not have the muscle. In the case of absence, it seems like a thin tendon similar to the medial area enlargement of psoas major muscle [10,9]. As a weak flexor of lumbar vertebrae, PSMI makes the spine slant and the pelvis bend, thereby, contributing to the stabilization of waist and hips. $[8,11]$. The presence of PSMI was reported $9 \%$ in black adult men and $96 \%$ in white adult men [12]. In their study on fetuses, Guerra et al., Reis, Bastos, \& Brito [13] found out that the muscle was present in $59,09 \%$ of the subjects. Moreover, there are some other studies in literature reporting the fact that race and gender differences may affect the presence of the muscle $[12,14]$. It's known that only a limited number of studies have examined the presence of PSMI and all of these studies were conducted on cadavers. It's quite remarkable that there's no studies in literature including the presence of the muscle in athletes apart from ordinary individuals.

This study aims to find out the presence of musculus psoas minor through MRI images obtained from the weightlifting athletes in Turkey.

\section{Materials and Methods}

The study included two groups consisting of 12 men and 12 women weightlifting athletes that have taken place in national and international weightlifting tournaments 
and that have actively and regularly participated in training programs in Olympic Preparation Center in Konya, Turkey. The demographic features of the groups are shown in Table 1. The ethics committee approval of the study depends on the decision dated 12-Apr-2016 numbered 017 by Ethics Committee of Medical Education Department of the Medical Faculty of the KTO Karatay University. The physical inspection of all volunteer participants was carried out by specialist physicians and all study groups were informed about the study.

Table.1. The morphometric measures of age and body of the participants in the study group (Mean $\pm \mathrm{SD}$ ).

\begin{tabular}{ccc}
\hline \multirow{2}{*}{$\begin{array}{c}\text { Morphometric } \\
\text { Features }\end{array}$} & \multicolumn{2}{c}{ Groups } \\
\cline { 2 - 3 } & Male Athletes (n 12) & Female Athletes (n 12) \\
\hline Age (year) & $19.0 \pm 2,3$ & $20,0 \pm 1,19$ \\
\hline Height $(\mathrm{cm})$ & $173.8 \pm 5,9$ & $161.1 \pm 5,8$ \\
\hline BW $(\mathrm{kg})$ & $78.9 \pm 15,3$ & $58.5 \pm 6,4$ \\
\hline BSA $\left(\mathrm{m}^{2}\right)$ & $1.928 \pm 0.1$ & $1.617 \pm 0.1$ \\
\hline BMI $\left(\mathrm{kg} / \mathrm{m}^{2}\right)$ & $26.1 \pm 5,04$ & $22.6 \pm 2,1$ \\
\hline BW: Body wign
\end{tabular}

\subsection{MRI Protocol}

For abdominal magnetic resonance imaging of participants, 1.5 Tesla magnetic imaging device (Magnetom Avanto; Siemens Healthcare Erlangen, Germany) located in the Radiology Department of Medical Faculty of the Necmettin Erbakan University was used. All participants were asked to stretch on the MRI platform in supine position. MRI was taken after 4-channel phased-array body coils were placed on abdominal region of each participant.

The imaging area was decided to be the proximal boundary of the $12^{\text {th }}$ thoracic vertebrae and distal boundary of trochanter minor of the femur. For the participants out of field of view (FOV), two consecutive imaging were taken from proximal to distal by using the same protocol. From the related region, firstly axial images (T1 parameters: TE: 10, TR: 1150, section thickness: 5mm, inter slice distance: $5 \mathrm{~mm}$, Matrix: 320*160, FOV: 206*330, NEX: 2) and then sagittal and coronal images were obtained to be used in radiological examination [15]. The imaging process was ended by recording of the MR images in DICOM format in CD-ROM.

\subsection{MRI Examination}

MRI images were initially examined by an expert of radiology. Axial section images, viewed on personal computer CD-ROMs, of the given muscle images were determined (musculus psoas major mean 33 (range: 29-36). All images were named from proximal to distal and saved in JPEG format in files for each participant.
Over the images, the limits between the given muscle and surrounding tissues were determined by using a graphic tablet (Uc-logicLapazz A4 professional design tablet, Japan) $[16,17,18,19]$ and all findings were saved (See Figure 1). The origo andinsertio of PSMI was not clear in MRI. The muscle was clearly observed on axial sections taken from $\mathrm{L} 4$.
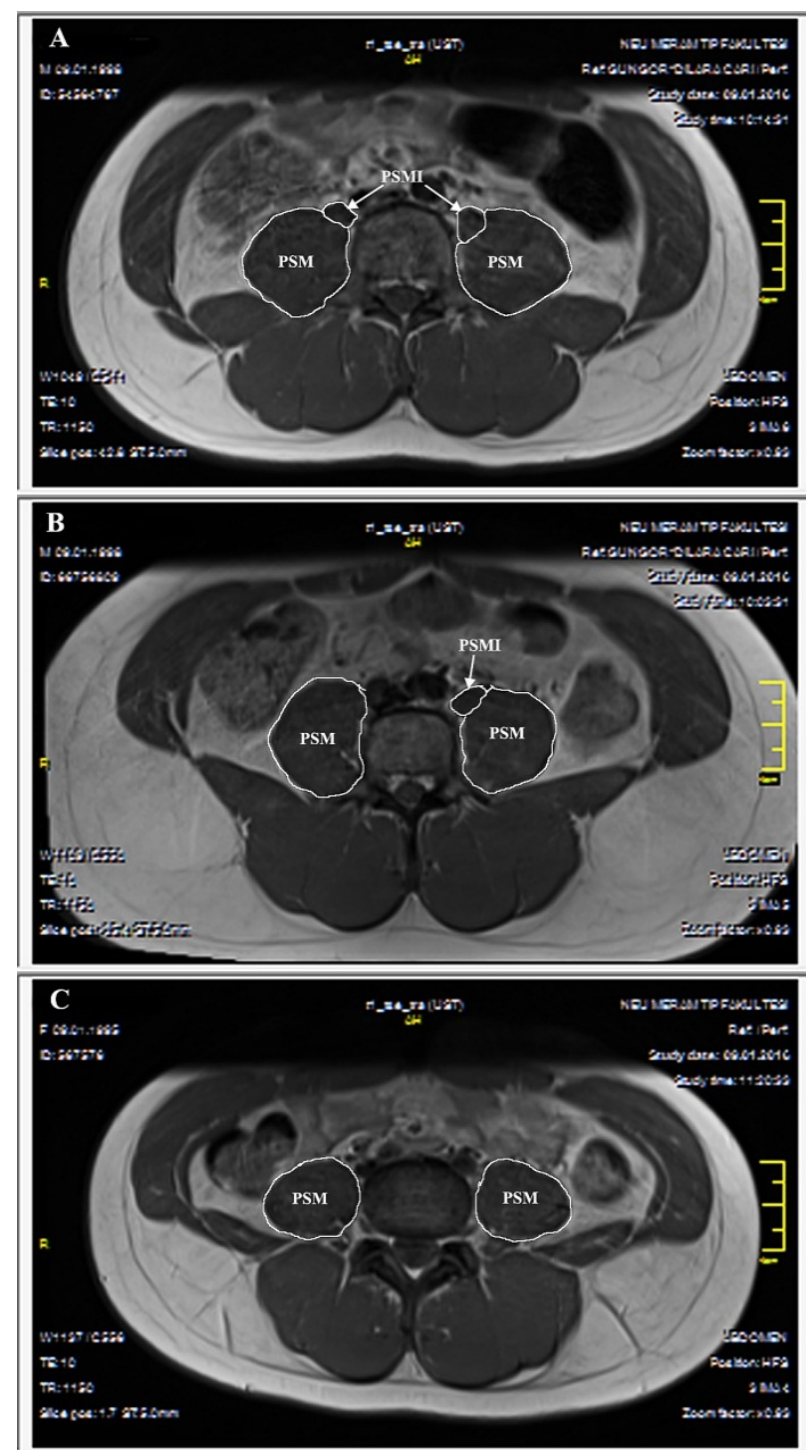

Figure 1. The bilateral (A), unilateral (B) presence and bilateral absence (C) of PSMI on axial MRI images taken from L4

\section{Statistical Analysis}

By using SPSS 24, arithmetic average and standard deviation values of the varieties regarding age, height, body weight, body surface area and body mass index of the study group were calculated (Table 1). Moreover, the frequency and percentages regarding the presence of PSMI were calculated (Table 2). 
Table 2. The presence of $\mathrm{m}$. psoas minor in the study groups

\begin{tabular}{|c|c|c|c|c|}
\hline \multirow{2}{*}{ GROUPS } & \multicolumn{3}{|c|}{ The presence of PSMI } & \multirow[t]{2}{*}{$\begin{array}{c}\text { The absence } \\
\text { of PSMI }\end{array}$} \\
\hline & $\begin{array}{c}\text { On both } \\
\text { sides }\end{array}$ & on right & on left & \\
\hline $\begin{array}{c}\text { Male } \\
\text { Athletes } \\
\text { (n 12) }\end{array}$ & $3(\% 25)$ & 1 & 2 & $6(\% 50)$ \\
\hline $\begin{array}{c}\text { Female } \\
\text { Athletes } \\
\text { (n 12) }\end{array}$ & $4(\% 33,3)$ & 1 & - & $7(\% 58.33)$ \\
\hline $\begin{array}{c}\text { General } \\
(24)\end{array}$ & $\begin{array}{c}7 \\
(\% 29.16)\end{array}$ & $\begin{array}{c}2 \\
(\% 8.33) \\
\end{array}$ & $\begin{array}{c}2 \\
(\% 8.33) \\
\end{array}$ & $13(\% 54.16)$ \\
\hline
\end{tabular}

PSMI: M.psoas minor.

\section{Results}

The demographic structure of the groups in the study is shown in Table 1.

By studying axial images of the participants, the presence of PSMI was analysed. In the study including 24 volunteer participants, we found that the muscle was on both sides of 7 , on the right side only of 2 and on the left side only of 2 of the total participants. The muscle was not present on 13 of the participants. We observed that PSMI was present on both sides of 3 , on the right side only of 1 and on the left side only of 2 of the men weightlifters whereas the muscle was present on both sides of 4 and on the right side only of 1 women weightlifters.

\section{Discussion}

We found no studies regarding the morphometric features of PSMI (section surface area, volume) are available in literature. There are various reports regarding the presence of PSMI. Guerra, Reis, Bastos, \& Brito [13], reported the presence was 59,09\% (75\% double-sided, $25 \%$ single-sided) in their study on fetuses. Moreover, the presence of the muscle was reported $26,7 \%$ in adults by Farias, Oliveira, Rocha, \& Caiaffo [14], 35\% (85\% double-sided, 15\% single-sided) by Sachin, Suchismita, \& Neelam, [20], 9\% in black adult men (50\% double-sided, $50 \%$ single-sided) and $96 \%$ in white adult men $(90 \%$ double-sided, 10\% single-sided) by Hanson, Magnusson, Sorensen, \& Simonsen, [12]. Regarding the studies reporting the absence of the muscle, Guerra, Reis, Bastos, \& Brito, [13] reported that in their study including 22 fetuses (7-9-month-old), the muscle was not present in $40,91 \%$ of the subjects. While Guerra, Reis, Bastos, \& Brito, [13] reported that PSMI is not present in 40,91\% of the fetuses and Rickenbacher, Landolt, \& Theiler, [21] reported that PSMI does not exist in 50\% of healthy individuals, Williams and Warrick [8], supposed that the rate could be more than $50 \%$. When racial and skin-color differences were taken into consideration, it was reported that the muscle was not present in $53,4 \%$ of the Japanese
[22], 73,3\% of the Brazilian [14], $65 \%$ of the Indians [20], $91 \%$ of black adult men and $4 \%$ of white adult men [12]. In the radiological evaluations, we found out that PSMI was not present on both sides of $50 \%$ of men weightlifters and $58.33 \%$ of women weightlifters (Table 2). The percentage regarding the absence of PSMI was in compliance with the literature.

There is a general opinion that double-sided PSMI is not present in $50 \%$ of healthy individuals approximately. When we consider the absence and the function of the muscle in the mentioned sport, we can say that this may be a disadvantage in the success of the athletes. Therefore, we think that checking the presence of the muscle while selecting athlete candidates will be an important approach.

In conclusion, the presence of PSMI was examined by MRI images taken from a limited number of athletes. In weightlifting and other branches of sports, which require lumbar stabilization, the absence of the muscle may be considered as a disadvantage in the success of athletes. Thus, we are in the opinion that new studies conducted by radiological and functional methods to find out the presence, functions and morphometric features of the muscle are needed.

\section{REFERENCES}

[1] Garhammer, J., \& Takano, B. (1992).Strength and power in sport. Komi, P. (Ed.), Encyclopaedia of sports medicine (Vol. 3, pp. 502-515). Great Britain, Blackwell Science.

[2] Burdett, RG. (1982). Biomechanics of the snatch technique of highly skilled and skilled weightlifters. Research Quarterly for Exercise and Sport, 53(3), 193-197. https://doi.org/10.1080/02701367.1982.10609339

[3] Dolan, P., Adams, M.A., \& Hutton, W.C. (1988). Commonly adopted postures and their effect on the lumbar spine. Spine, 13(2), 197-201.

[4] Wan, Q., Lin, C., Li, X., Zeng, W., \& Ma, C. (2015). MRI assessment of paraspinal muscles in patients with acute and chronic unilateral low back pain. The British journal of radiology, 88(1053), 1-7. https://doi.org/10.1259/bjr.20140 546

[5] Garhammer, J., \& Taylor, L. (1984). Center of pressure movements during weightlifting. 2. International Symposium on Biomechanics in Sports, 2, 279-291.

[6] Calhoon, G., \& Fry, A.C. (1999). Injury rates and profiles of elite competitive weightlifters. Journal of Athletic Training, 34(3), 232-238.

[7] Greene, H.S., Cholewicki, J., Galloway, M.T., Nguyen, C.V., \& Radebold, A. (2001). A history of low back injury is a risk factor for recurrent back injuries in varsity athletes. The American journal of sports medicine, 29(6), 795-800. https://doi.org/ 10.1177/03635465010290062001

[8] Williams, P., \& Warwick, R. (1992). Gray's anatomy. London: Churchill Livingstone, 
[9] Arınc1, K., \&Elhan, A. (2001). Anatomi 1. Ankara, Günes Kitapevi.

[10] Dere, F. (1990). Anatomi 1 (2nd ed). Adana, Nobel T1p Kitapevi.

[11] Moore, K.L., Dalley, A.F., \& Agur, A.M.R. (2014). Upperlimb. Clinically oriented anatomy. Philadelphia: Wolters Kluwer/Lippincott Williams \& Wilkins.

[12] Hanson, P., Magnusson, S.P., Sorensen, H., \& Simonsen, E.B. (1999). Anatomical differences in the psoas muscles in young black and white men. Journal of anatomy, 194(2), 303-307.

https://doi.org/10.1046/j.1469-7580.1999.19420303.x

[13] Guerra, D.R., Reis, F.P., Bastos, A., \&Brito, C.J. (2012). Anatomical study on the psoas minor muscle in human fetuses.Int. J. Morphol, 30(1), 136-139.

[14] Farias, M., Oliveira, B.D.R., Rocha, T.D.S., \&Caiaffo, V. (2012). Morphological and morphometric analysis of psoas minor muscle in cadavers.J Morphol Sci,29(4), 202-205.

[15] Sanchis-Moysi, J., Idoate, F., Izquierdo, M., Calbet, J.A., \& Dorado, C. (2011). Iliopsoas and gluteal muscles area symmetric in tennis players but not in soccer players. Plos one, 6(7), 1-10.https://doi.org/10.1371/journal.pone.002285

[16] Peltonen, J.E., Taimela, S., Erkintalo, M., Salminen, J.J., Oksanen, A., \&Kujala, U.M. (1997). Back extensor and psoas muscle cross-sectional area, prior physical training, and trunk muscle strength-a longitudinal study in adolescent girls. European journal of applied physiology and occupational physiology, 77(1), 66-71.

[17] Marras, W.S., Jorgensen, M.J., Granata, K.P., \&Wiand B. (2001). Female and male trunk geometry size and prediction of the spine loading trunk muscles derived from MRI. Clinical Biomechanics, 16(1), 38-46.

[18] Hides, J., Stanton, W., Freke, M., Wilson, S., McMahon, S. \& Richardson, C. (2007). MRI study of the size, symmetry and function of the trunk muscles among elite cricketers with and without low back pain. British Journal of Sports Medicine, 42(10), 809-813. https://doi.org/10.1136/bjsm.20 07.044024

[19] Asaka, M., Usui, C., Ohta, M., Takai, Y., Fukunaga, T., \& Higuchi, M. (2010). Elderly oarsmen have larger trunk and thigh muscles and greater strength than age-matched untrained men. European Journal of Applied Physiology, 108(6), 1239-1245. https://doi.org/10.1007/s00421-009-1337-6

[20] Sachin, P., Suchismita, G., \&Neelam, V. (2015). Biometrics of psoas minor muscle in North Indian population.Journal of Surgical Academia, 5(1), 14-8.

[21] Rickenbacher, J., Landolt, AM., \& Theiler, K. (2013). Applied anatomy of the back. Springer-Verlag .https://doi.org/10.1007/978-3-662-05791-

[22] Mori, M. (1964). Statistics on the musculature of the Japanese. Okajimas Folia Anatomica Japonica, 40(3), 195-300.https://doi.org/10.2535/ofaj1936.40.3 195

\footnotetext{
${ }^{\mathrm{i}}$ The paper presented orally at the $9^{\text {th }}$ International Biomechanics Congress 19-22 September 2018, Eskişehir, Turkey.
} 